\title{
New start-up curves for a 200 MW steam boiler with natural circulation
}

\author{
Piotr Dzierwa ${ }^{1}$ \\ ${ }^{1}$ Institute of Thermal Power Engineering, Cracow University of Technology, Cracow, Poland
}

\begin{abstract}
The paper shows the method of determining the start-up curves of a steam boiler, which enables its faster start-up. Faster temperature changes cause thermal stress, especially in thick-walled boiler elements. Critical elements that limit the rate of change of working fluid units include drums, outlet chamber, injection chamber, fresh steam superheater of steam coolers, tees and valve casings, rotor and turbine casing. The walls of these elements have the thickest walls due to the high pressure values occurring in them during operation. Allowable changes in temperature and pressure during start-up and shut-down can be determined by the European Standard EN 12952-3. The article shows how the start-up curves of a steam boiler can be determined using the European Standard and the method proposed by the author. Calculation results show that the starting time of the analyzed block can be significantly shortened.
\end{abstract}

\section{Introduction}

Due to the increasing share of wind farms in electricity generation, a need arises to speed up the start-up process in conventional thermal power plants. This results from great variations in the amount of power supplied to the power grid by wind turbines [3-6]. During start-up and shutdown, as well as at changes in loads, considerable thermal stresses arise in the power boiler thick-walled pressure components operating at high temperatures. The critical components that limit the rate of changes in the working fluid parameters include the natural circulation boiler drums, water separators in once-through boilers, chambers of steam injection coolers, T-pipes and valve housings [3]. Considering high-pressure values and large diameters, the walls of these elements are much thicker compared to the boiler other components operating under the same pressure. Considerable differences in temperature occur in very thick walls. The life of the elements may be reduced dramatically if heating and cooling rates are too high. The biggest stresses and strains usually occur at the edges of openings, where, after a longer period of operation, cracks may develop due to low-cycle fatigue. The stresses and strains determine allowable heating and cooling rates for pressure components. Start-up and shutdown should be performed in a manner that ensures that :

- the selected rate of heating (cooling) the boiler components from the initial state to the design value should ensure that allowable stresses and temperatures are not exceeded,

- energy losses are as small as possible,

- the process is safe for staff and equipment.
The regulations concerning the optimum performance of the power unit start-up and shutdown processes have not been developed in Poland yet. For most boilers, allowable rates are specified in the operating instructions prepared by the manufacturer. As a rule, they are constant values which are independent of the nature of any time-dependent changes in pressure in a thick-walled component. The methods that have already been worked out to specify the optimum procedure for carrying out the heating or cooling process concern flat or cylindrical walls. In the boiler technology, the problem that has to be faced most often is a weakened cylindrical or spherical component. The application of optimization methods developed for components with simple shapes is burdened with too big errors. Such methods may only be used to estimate the limit values of start-up or shutdown parameters. The allowable rates of the element heating and cooling determined according to the German regulations concerning boilers (TRD-301) or to the European standard EN 12952-3 is based on the assumption of a quasi-stationary temperature field in the wall of a structural component $[1,2]$. This is difficult to achieve in practice as this state settles in the pressure element wall only after it has been heated at a constant rate for 20-30 minutes. Due to high rates of changes in steam temperatures in time, the quasi-stationary temperature field is very seldom to occur [7, 8]. Moreover, the element heating and cooling times determined based on the TRD-301 regulations or the EN 12952-3 standard can cause excessive stress on the edges of the holes. This, in turn, leads to the shorter service life of pressure components of the boiler. The German boiler regulations TRD-301 make it possible to determine allowable

\footnotetext{
${ }^{*}$ Corresponding author: pdzierwa@pk.edu.pl
} 
cooling and heating rates for the boiler pressure elements for several selected shapes of structural components. The criterial point is located on the hole internal surface in the plane passing through the pressure element longitudinal axis and the opening axis. However, calculations performed using the Finite Element Method indicate that as heating proceeds, the biggest total stresses may also occur on the hole edge in the plane perpendicular to the pressure component axis and passing through the hole edge axis. Another drawback of the TRD-301 regulations is the assumption of a constant thermal stress concentration coefficient $\alpha_{T}=2$, i.e. like in the case of an infinite plate with a hole on the thickness along which temperature drops linearly. The fields of both temperature and stresses in the area of holes are complicated due to the occurrence of connecting pipes. It also turns out that for a threedimensional temperature field the thermal stress concentration coefficient in a quasi-steady state depends on the value of the heat transfer coefficient $h$ on the external surface [16]. The TRD-301 regulations do not take this fact into account at all. Although the European standard EN 12952-3 takes into account the dependence of the thermal stress concentration coefficient $\alpha_{\mathrm{T}}$ on the heat transfer coefficient $h$, the quasi-steady temperature field is still adopted in this standard. For components with complicated shapes, if pressure-related stresses are to be calculated, stress concentration coefficients are used making it possible to find the maximum value of these stresses in the concentration zones. In real conditions, the value of the stresses can be calculated using the Finite Element Method (FEM) structural analysis. It often turns out that the values of stress concentration coefficients taken from the TRD-301 or literature [4] deviate considerably from those determined using the FEM. Due to the transient nature of temperature changes, it is very important to monitor stress conditions in thick-walled walls of criteria elements [9-11]. This requires precise determination of transient temperature changes of the working medium [12-15].

The above-mentioned limitations of the TRD-301 regulations and the EN 12952-3 standard make it impossible to calculate allowable rates of heating and cooling the boiler thick-walled elements at which real stresses on the hole edge calculated using the FEM do not exceed prescribed allowable stress values. Therefore, an own method of determining the optimum changes in the fluid temperatures during the heating and cooling of pressure elements was developed at which the total of thermal and pressure-related stresses on the hole edge does not exceed the allowable values. In this paper, the start-up pressure and temperature curves were determined for the critical thick-walled components the drums and outlet headers - using a standard EN 12952-3 and the method developed in papers. The objective of an extensive structural analysis of boiler pressure components was to improve the flexibility of the power unit.

\section{Start-up curves of OP-650-012 boiler}

The OP-650-012 boiler is a steam boiler fired with pulverized hard coal. Boiler achieves design electrical power $210 \mathrm{MWe}$. When designing the OP-650 boilers, the possibility of fast start-ups from cold, warm or hot states was not taken into account. The current operating manual of this boiler allows for heating with a constant rate of $1 \mathrm{~K} / \mathrm{min}$ for the fluid temperature in the boiler drum, no matter what the pressure in the boiler is. This results in a significant extension of the start-up time. The time changes of generator active power, superheater steam mass flow, the pressure in the boiler drum, the pressure in the superheater, during the start-up of the OP-650-012 from the cold state are shown in Fig. 1.

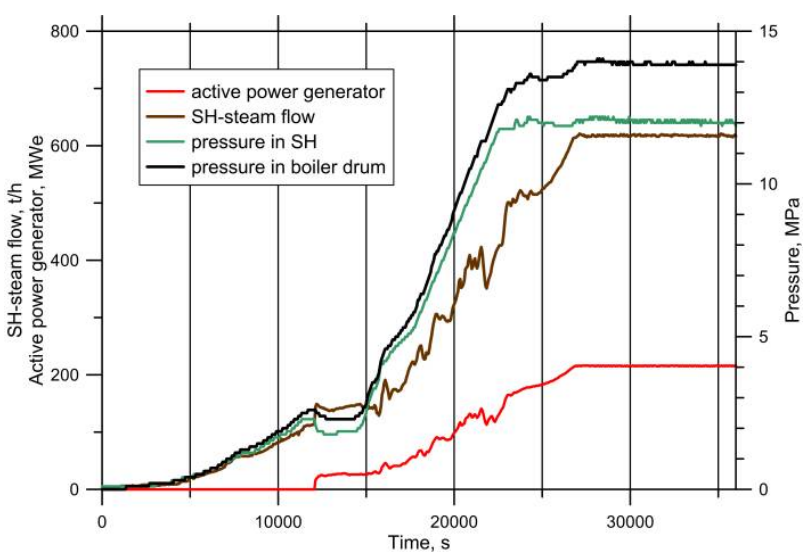

Fig. 1. Start-up curves of the OP-650-012 boiler from the cold state.

It can be seen from Fig. 1 that the start-up time of the OP-650-012 boiler is about 7.5 hours. The start-up duration was calculated as the time interval between the pressure rise in the drum and the moment when the drum pressure reached the nominal value.

\section{A new method of determination of the optimum steam curves during the drum heating}

The permissible stresses values during start-up and shutdown of the OP-650-012 boiler have been determined from the standard EN 12952-3. First, the allowable rates of temperature changes during the startup of the boiler drum were determined. Next, the steam temperature curve $T_{f}(t)$ was found from the solution of the following differential equation

$$
\frac{d T_{f}}{d t}=f(p)
$$

with

$$
f(p)=\frac{p_{2} v_{T 1}-p_{1} v_{T 2}}{p_{2}-p_{1}}+\frac{v_{T 2}-v_{T 1}}{p_{2}-p_{1}} p
$$

Pressure $p$ depends on the temperature in the case of a drum containing water with the saturation temperature. The gauge pressure $p_{l}$ at the beginning of the start-up process was $0 \mathrm{MPa}$, while at the end of the process it 
was $p_{2}=15.95 \mathrm{MPa}$. The pressure in the outlet header is by about $15 \%$ lower than in the boiler drum. The Eq. (1) has been solved with the Runge-Kutta method. Figure 3 and Table 1 shows the allowable heating and cooling rates $v_{T}$ for the boiler drum obtained by using the standard EN 12952-3. The drum is made of low alloy steel, grade $15 \mathrm{NCuMNb}(\mathrm{K} 32 \mathrm{Nb})$. The chemical composition of the steel is as follows: $\mathrm{C} \leq 0.17 \%, 0.25 \leq$ $\mathrm{Si} \leq 0.5 \%, 0.8 \leq \mathrm{Mn} \leq 1.2 \%, 0.035 \% \leq \mathrm{P}, 0.035 \% \leq \mathrm{S}$, $0.5 \leq \mathrm{Cu} \leq 0.8 \%, 0.25 \leq \mathrm{Mo} \leq 0.5 \%, 1.0 \leq \mathrm{Ni} \leq 1.3 \%$.

Table 1. The allowable rates of fluid temperature changes for a drum of OP-650-012 boiler.

\begin{tabular}{|l|c|c|c|c|}
\hline \multirow{2}{*}{} & \multicolumn{2}{|c|}{ Start-up } & \multicolumn{2}{c|}{ Shutdown } \\
\cline { 2 - 5 } & Beginning & End & Beginning & End \\
\hline \multicolumn{5}{|c|}{ Boiler drum } \\
\hline$p, \mathrm{MPa}$ & 0 & 15.95 & 15.95 & 0 \\
\hline$v_{T}, \mathrm{~K} / \mathrm{min}$ & 4.52 & 13.5 & -3.91 & -12.91 \\
\hline$\Delta T, \mathrm{~K}$ & -26.41 & -79.82 & 22.88 & 76.3 \\
\hline \multicolumn{5}{|c|}{ Outlet header } \\
\hline$p, \mathrm{MPa}$ & 0 & 13.65 & 13.65 & 0 \\
\hline$v_{T}, \mathrm{~K} / \mathrm{min}$ & 3.51 & 4.72 & -3.51 & -4.72 \\
\hline$\Delta T, \mathrm{~K}$ & -33.84 & -45.33 & 33.84 & 45.33 \\
\hline
\end{tabular}

The outlet header is made of boiler steel, grade 13CrMo44. The chemical composition of the steel is as follows: $0.1 \mathrm{C} \leq 0.18 \%, 0.15 \leq \mathrm{Si} \leq 0.35 \%, 0.4 \leq \mathrm{Mn} \leq$ $0.7 \%, 0.04 \% \leq \mathrm{P}, 0.04 \% \leq \mathrm{S}, 0.7 \leq \mathrm{Cr} \leq 1.0 \%, 0.4 \leq$ Mo $\leq 0.5 \%$.

The results of calculations of permissible temperature differences, as well as heating and cooling rates depending on the pressure, are presented in Table 1. These values have been determined using the EN 129523 standard. Next, the temperature changes of the fluid during the start-up were determined for the drum and the outlet header. The heating of pressure components is carried out in such a manner that the total circumferential stresses on the hole edge, in the stress concentration point, caused by pressure and temperature do not exceed permissible values. Values of stress concentration coefficients were determined for elements taking into account the actual 3D geometry using the finite element method (FEM). These values made it possible to determine the permissible rates of temperature changes in the criteria elements. However, the FEM analysis indicates that the thermal stress concentration coefficients depend not only on the component geometry but also on the heat transfer coefficient on the inner surface. The optimum temperature and pressure changes during start-up of the pressure vessel should be determined concerning the total circumferential stress (caused by the difference in wall temperature and internal pressure) at the point of their concentration. The optimum temperature curves for the live steam superheater outlet header and boiler drum are presented in Fig. 2. Figure 3 shows the pressure changes in the OP-650-012 boiler header and boiler drum during optimum heating.

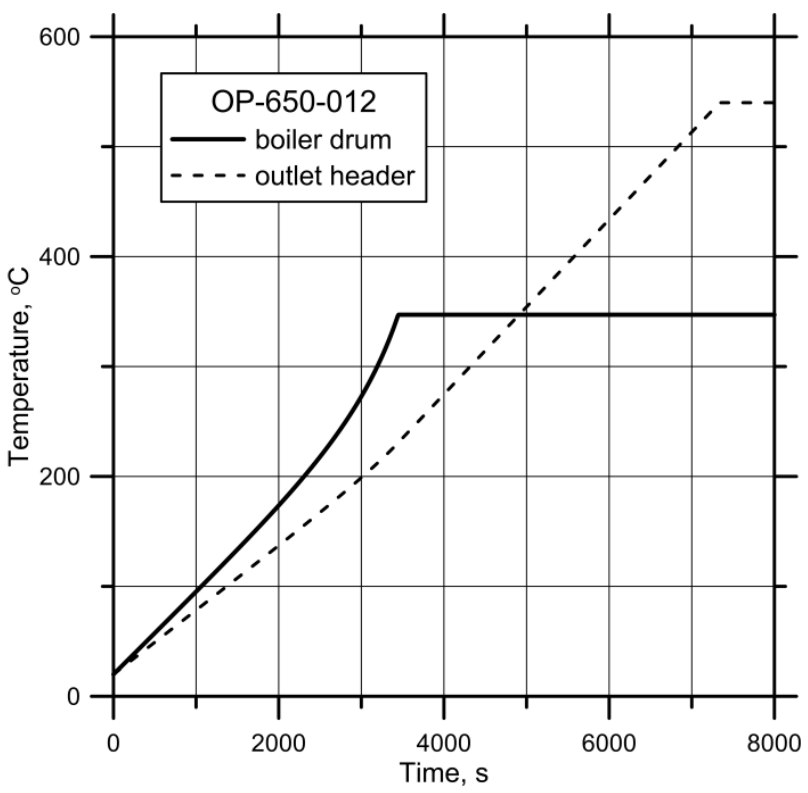

Fig. 2. Steam temperature changes for the OP-650-012 boiler drum and outlet header during start-up according to the proposed method.

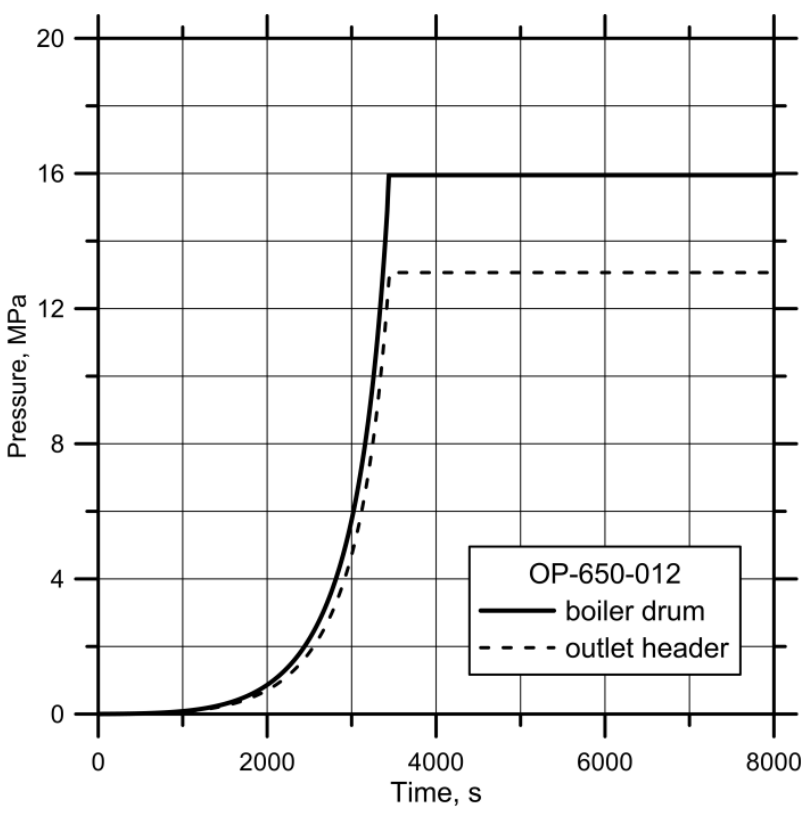

Fig. 3. Steam pressure changes for the OP-650-012 boiler drum and outlet header during start-up according to the proposed method.

The optimum outlet header heating time is equal to 2 hours and is two times higher than for boiler drum (Fig. 2 ). Pressure variations in the superheater outlet header as a function of time corresponding to a change of pressure in the drum. The pressure in the header is reduced by $15 \%$ compared with the value of pressure in the drum. It should be stressed that the effect of pressure on the optimum course of vapour temperature in the chamber is negligible since the thickness of the header wall is 100 $\mathrm{mm}$, and the inner diameter is only $308 \mathrm{~mm}$ (Fig. 4). Stresses due to pressure at the points $\mathrm{P}_{1}$ and $\mathrm{P}_{2}$ are, 
therefore, very small and do not influence optimum temperature changes. Considering that the present startup time of the boiler is 7.5 hours, it is possible to make it about three times shorter.

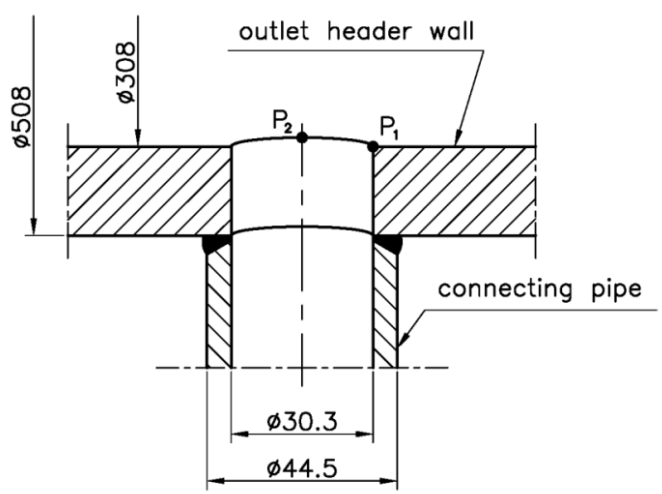

Fig. 4. Diagram of the analyzed connection between the junction of the outlet header with connecting pipe; $\mathrm{P}_{1}-$ criterial point taken into account in the Standard EN 12952-3, $\mathrm{P}_{2}-$ additional criterial point.

The boiler shutdown may be performed at any rate. During the shutdown, thermal and pressure-related stresses are summed up. Due to the reduction in the boiler pressure, the permissible cooling rates for the drum and outlet header may be very high. The boiler shutdown rate, i.e., a reduction in the steam pressure and the temperature is limited by factors other than thermal stresses. The problem of cooling optimization of boiler pressure components is less important, due to the large mass of water and metal in the boiler so that fast cooling of the boiler during normal operation is impossible.

\section{Analysis of the temperature and stress field in the OP-650-012 boiler drum - constant heating rate}

As shown in the previous chapter, the outlet header will be the limiting element of the boiler start-up. In this paragraph, the transient thermal-strength analysis of the OP-650-012 boiler drum was carried out for starting curves adjusted to the boiler outlet header heating time changes. The boiler start-up time from a cold state is 7300 seconds. The fluid temperature in the drum varies at a constant rate from the initial value $20^{\circ} \mathrm{C}$ to the nominal temperature of $340^{\circ} \mathrm{C}$. The heat transfer coefficient is equal to $3000 \mathrm{~W} /\left(\mathrm{m}^{2} \cdot \mathrm{K}\right)$. The FEM calculations were carried out using the Ansys 18.2 software. The mesh of elements used in the calculation is shown in Fig. 9. Figs. 5-8 shows the thermo-physical properties of steel grade $15 \mathrm{NCuMNb}$, i.e.:

- thermal conductivity

- density

- heat capacity

- Young's modulus

- yield strength

- Poisons ratio

- linear thermal expansion coefficient as a function of temperature.

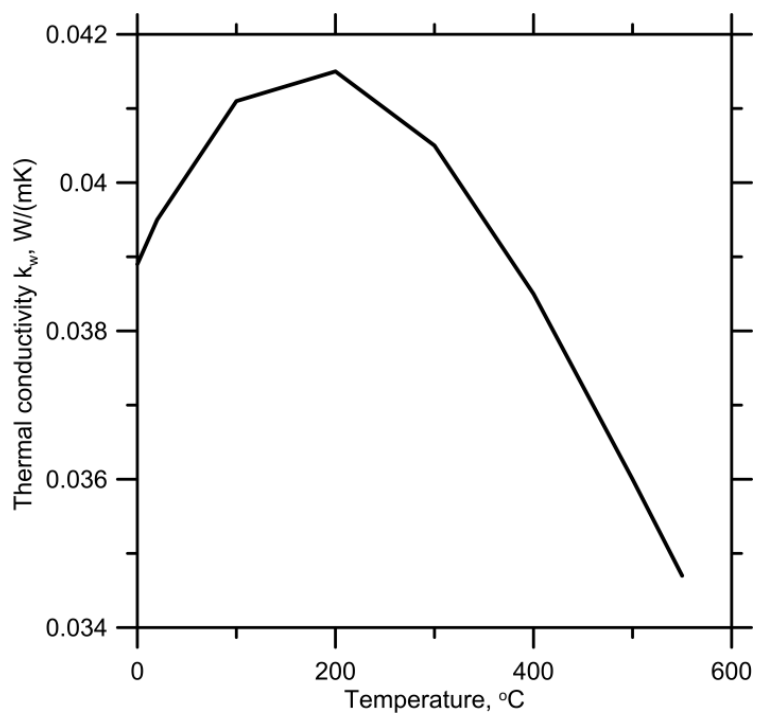

Fig. 5. Temperature dependence of thermal conductivity values for steel $15 \mathrm{NCuMNb}$.

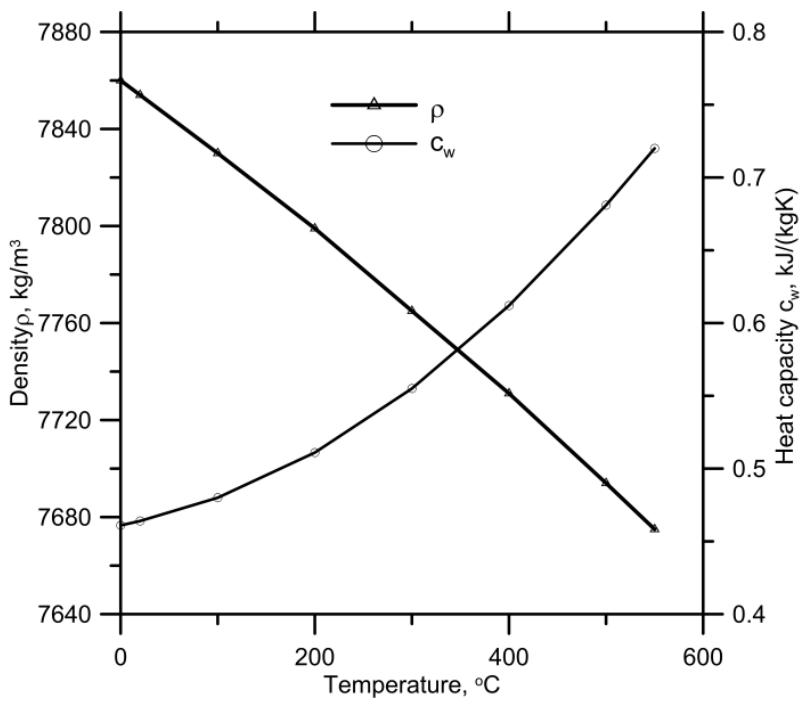

Fig. 6. Temperature dependence of density and heat capacity values for steel $15 \mathrm{NCuMNb}$.

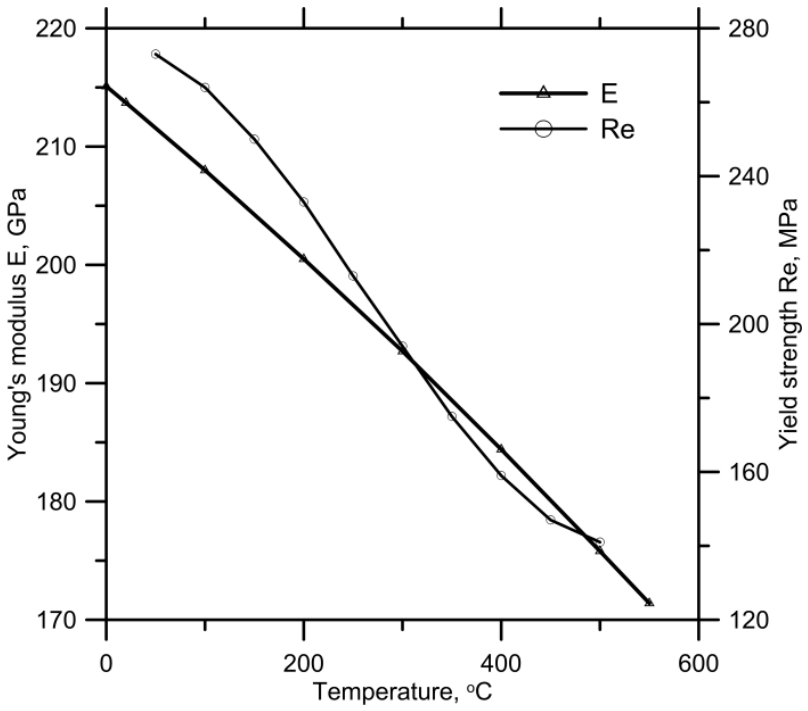

Fig. 7. Temperature dependence of Young's modulus and yield strength values for steel $15 \mathrm{NCuMNb}$. 


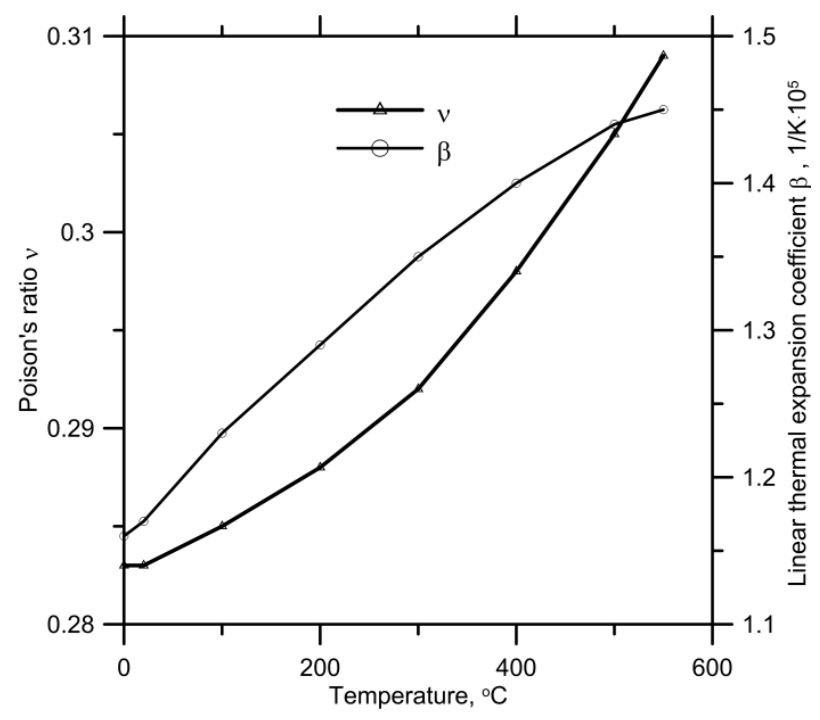

Fig. 8. Temperature dependence of Poisons ratio and linear thermal expansion coefficient values for steel $15 \mathrm{NCuMNb}$.

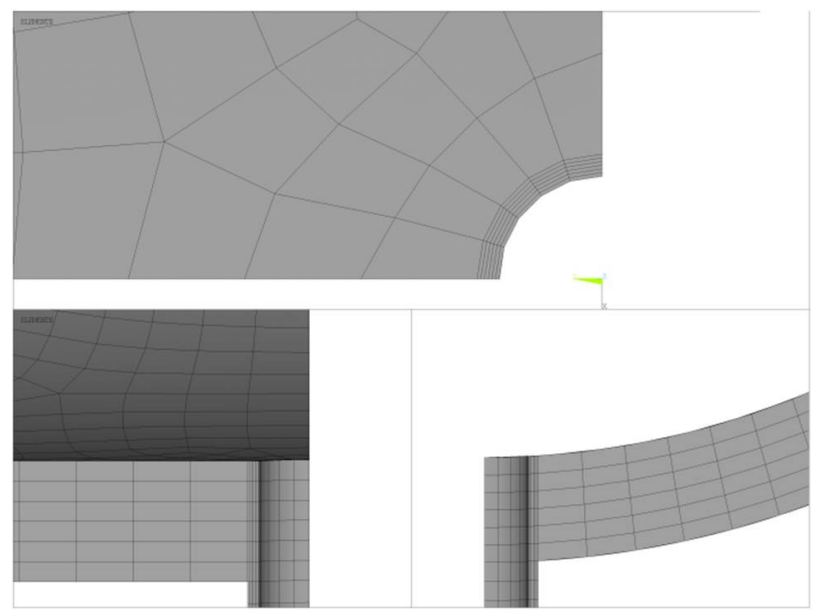

Fig. 9. Mesh of finite elements used to analyze the drum down comer junction.

The EN 12952-3 standard was used to determine the permissible stresses limits for the startup $\left(\sigma_{a l}=-186\right.$ $\mathrm{MPa})$ and shutdown $\left(\sigma_{a l}=537 \mathrm{MPa}\right)$ Fig. 11 . The values of total circumferential stresses due to the thermal and pressure loads were calculated at the points $\mathrm{P}_{1}$ and $\mathrm{P}_{2}$ similarly as for the outlet header (Fig. 4) and compared with the permissible values in Fig. 11. Analysis of the results presented in Fig. 11 indicates that the stresses at points $P_{1}$ and $P_{2}$ are less than the limit values. The calculations take into account the pressure changes over time. Temperature changes on the inner and outer surface of the cylindrical part of the drum are shown in Fig 10. Figures 12 and 13 show the distribution of the temperature and von Misses stress field after 2000 seconds from the start of boiler start-up. Fig. 12 shows that the wall of the downcomer tube, which is much thinner than the wall thickness of the drum, heats up the fastest. The stress field analysis illustrated in Fig. 13 shows that the equivalent stresses reach their highest value at point $\mathrm{P}_{2}$. The stress concentration at the edge of the hole is of a local character (it causes the stress field to be too high at a short distance from the hole).

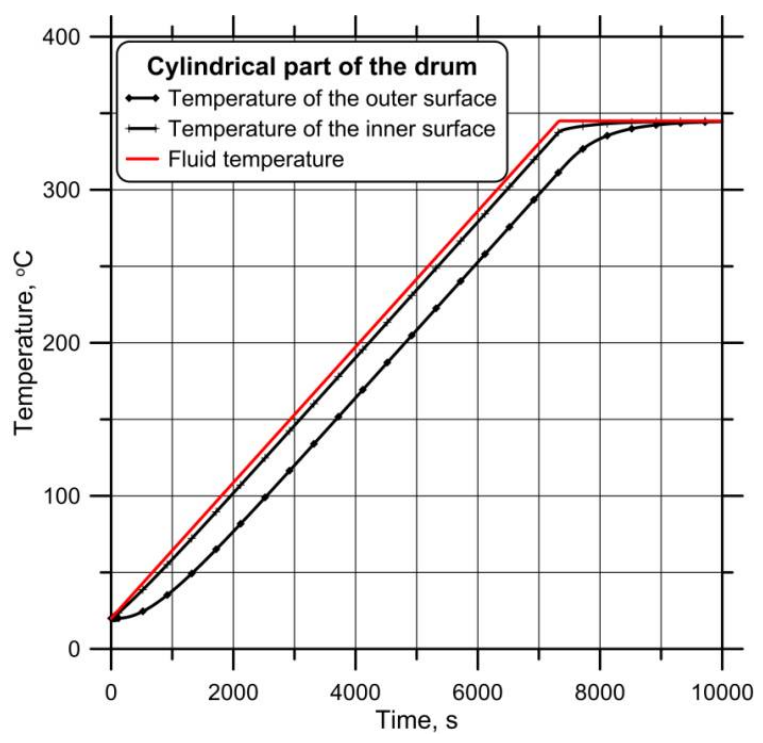

Fig. 10. Time changes in steam temperature during the OP650-012 boiler drum start-up and in temperatures of the inside and outside surfaces of the cylindrical part of the drum.

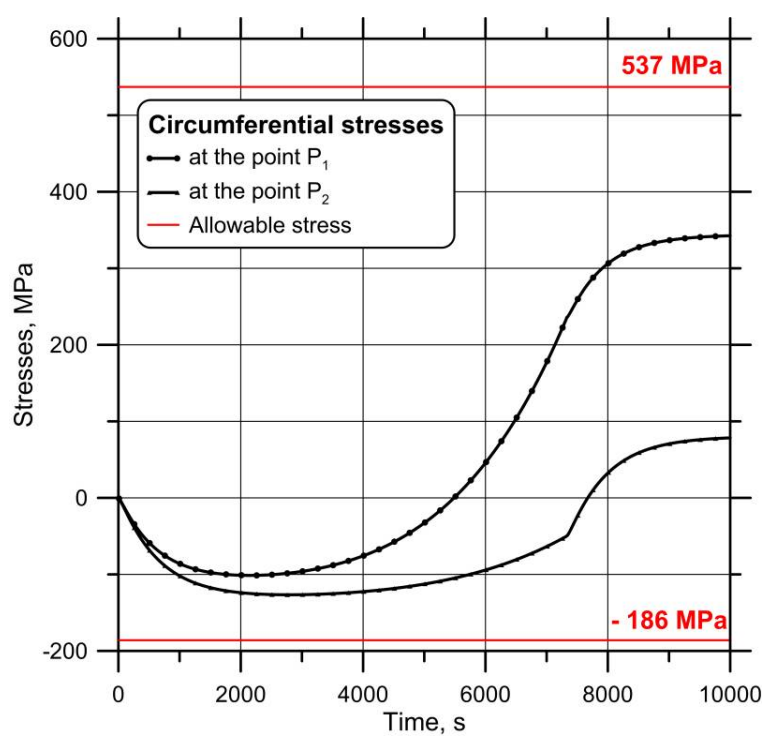

Fig. 11. Total circumferential stress due to thermal and pressure loads at points $\mathrm{P}_{1}$ and $\mathrm{P}_{2}$ during the OP-650-012 boiler start-up.

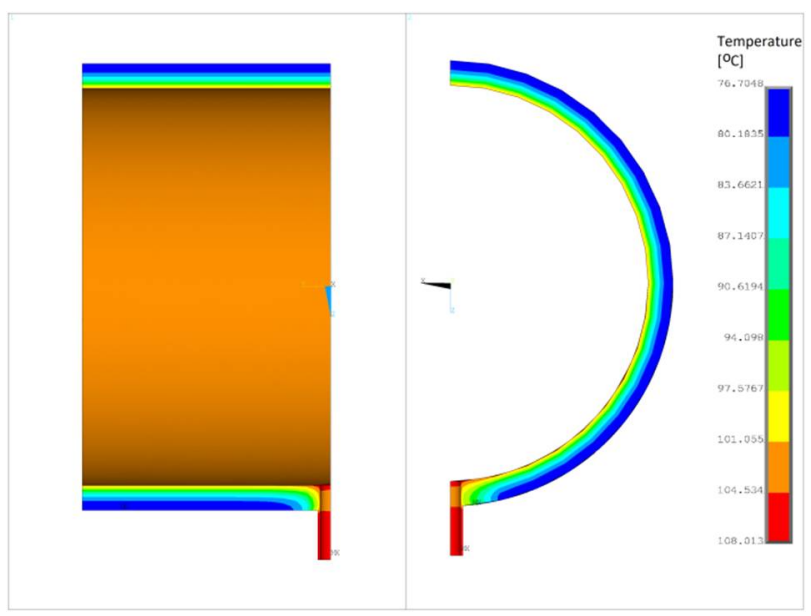

Fig. 12. Temperature distribution in the drum cross-section after $2000 \mathrm{~s}$. 


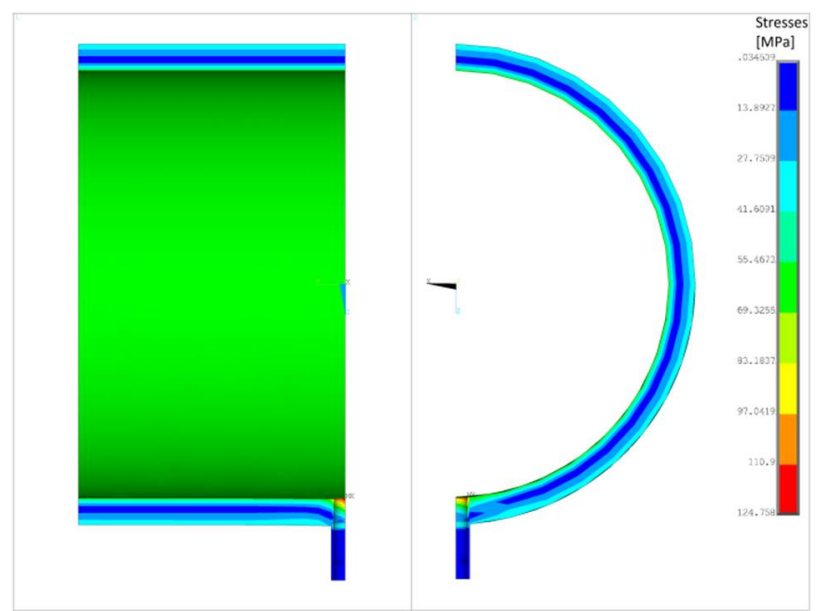

Fig. 13. Distribution of equivalent von Mises stress in time $4000 \mathrm{~s}$.

The conducted calculations show that the existing temperature difference on the drum circumference influences slightly the stress condition of the joint between the drum and the outlet pipe, i.e., in the area of the highest stress concentration. Concluding, the scheduled temperature and pressure changes can be achieved practically.

\section{Conclusions}

The paper analyses the process of OP-650-012 boiler start-up. The method of determination of start-up curves, i.e. time changes in temperature and pressure of the working medium, was shown. Analyses and calculations were made for two criteria elements of the boiler, for the outlet header of the final super heater and boiler drum. In the analysis of start-up acceleration possibilities, the European Standard EN 12952-3, as well as our own method of start-up optimization, were used.

The results show that the start-up time can be reduced from 7.5 hours to just over 2 hours. For the boiler in question, the start-up time is limited by the stresses in the outlet header of the final superheater. When the start-up is carried out by the start-up curves determined for the outlet header, the maximum absolute value of circumferential stresses at the hole edge of the drum - downcomer junction is much lower than the allowable stress.

\section{References}

1. TRD 301, Zylinderschalen unter innerem Überdruck. Technische Regeln für Dampfkessel (Heymanns Beuth, Köln - Berlin, Germany, 143185, 2001)

2. European Standard EN 12952-3, Water-tube boilers, and auxiliary installations. Part 3: Design and calculation for pressure parts (European Committee for Standardization, Brussels, 2012)

3. P. Dzierwa, J. Therm. Stresses 39, 874-886 (2016)

4. J. Taler, P. Dzierwa, ASME J. Pressure Vessel Technology 137, 011202-1-8 (2014)
5. J. Taler, P. Dzierwa, Int. J. Energ. Res. 35, 897-908 (2011)

6. P. Dzierwa, M. Trojan, D. Taler, K. Kamińska, J. Taler, J. Therm. Sci. 25, 380-388 (2016)

7. D. Taler, K. Kaczmarski, J. Therm. Sci. 25, 549-557 (2016)

8. J. Taler, W. Zima, M. Jaremkiewicz, J. Therm. Stresses 39, 386-397 (2016)

9. J. Taler, P. Dzierwa, D. Taler, M. Jaremkiewicz, M. Trojan, Monitoring of thermal stresses and heating optimization including industrial applications (Nova Science Publishers, New York, 2016)

10. J. Taler, D. Taler, K. Kaczmarski, P. Dzierwa, M.Trojan, T. Sobota, Energy 160 500-519 (2018)

11. T. Sobota, Heat Transfer Eng. 39, 1260-1271 (2018)

12. J. Taler, D. Taler, Measurement of heat flux and heat transfer coefficient, Heat flux: processes, measurement techniques, and applications (Nova Science Publishers, 1-103, New York, 2012)

13. M. Jaremkiewicz, D. Taler, T. Sobota, Int. J. Therm. Sci. 87, 241-250 (2015)

14. M. Jaremkiewicz, Heat Mass Transfer 53, 887-897 (2017)

15. M. Jaremkiewicz, J. Taler, Heat Transfer Eng. 39, issues 13-14, 1227-1234 (2018)

16. M. Trojan, D. Taler, Fuel 150, 75-87 (2015) 